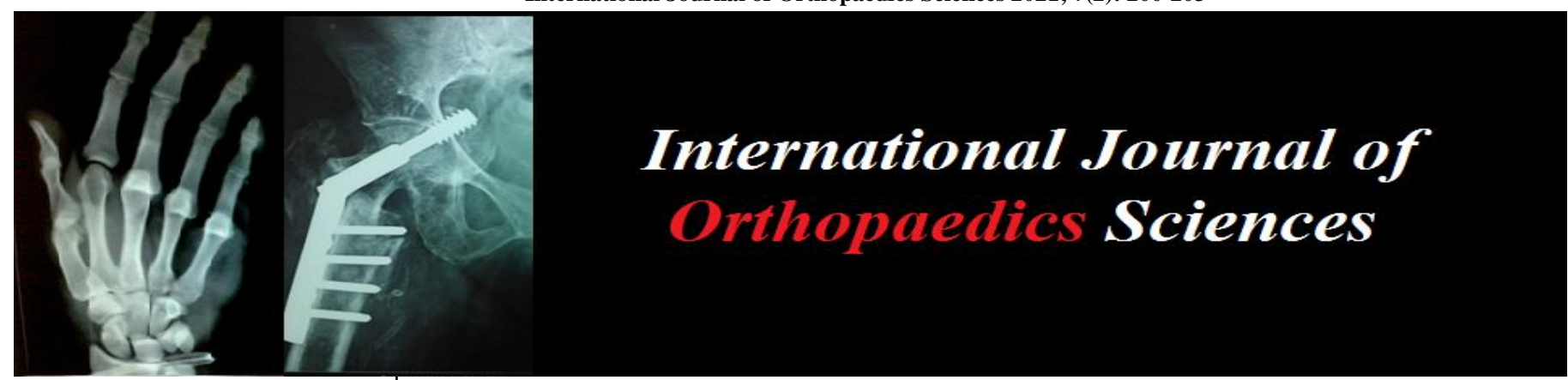

E-ISSN: 2395-1958

P-ISSN: 2706-6630

IJOS 2021; 7(2): 200-203

(C) 2021 IJOS

www.orthopaper.com

Received: 22-02-2021

Accepted: 25-03-2021

Dr. Gaurav C Mendon

Junior Resident, Department of

Orthopaedics, AJ Institute of

Medical Sciences, Mangalore,

Karnataka, India

Dr. Shetty Suraj Ravindra

Assistant Professor, Department of Orthopaedics, AJ Institute of

Medical Sciences, Mangalore,

Karnataka, India

Dr. Kaveesh P Shetty

Junior Resident, Department of Orthopaedics, AJ Institute of

Medical Sciences, Mangalore,

Karnataka, India

Dr. Shree Krishnananda Sagar Junior Resident, Department of Orthopaedics, AJ Institute of Medical Sciences, Mangalore

Karnataka, India
Corresponding Author: Dr. Gaurav C Mendon Junior Resident, Department of Orthopaedics, AJ Institute of Medical Sciences, Mangalore, Karnataka, India

\section{Distal femur giant cell tumor - therapeutic challenge: A case report}

\author{
Dr. Gaurav C Mendon, Dr. Shetty Suraj Ravindra, Dr. Kaveesh P Shetty \\ and Dr. Shree Krishnananda Sagar
}

DOI: https://doi.org/10.22271/ortho.2021.v7.i2c.2633

\section{Abstract}

Background: Giant cell tumor (GCT) is a benign, locally aggressive bone tumor with rarely tendency to metastasize. The location of giant cell tumors in areas like distal femur, proximal tibia, etc. makes the management of the tumor challenging. Inadequate curettage may lead to recurrence of the tumor, which has to be kept in mind even before planning for surgery.

Aims and Objectives: Large giant cell tumor management has always been difficult. Even more difficult is tackling the complication like recurrence. This case was studied to know how the extended curettage with phenol crystal helps in reducing the risk of recurrence of GCT.

Methods: An 18 year old male clinically and radiologically diagnosed to have GCT in the medial condyle right distal femur was taken up for extended curettage with phenol crystal wash, bone grafting and cementation with allograft mixed with bone cement and medial condylar plating for right distal femur. Followed by a histo-pathological examination of the curetted sample. Regular follow-up of the patient was done at 1, 3, 6, 12 and 18 months post operatively to assess for recurrence of the tumor.

Result: Histo-pathologically the diagnosis of giant cell tumor was confirmed. At regular follow-ups of 1, 3, 6, 12 and 18 months post operatively and also an MRI done at 12 months follow-up period showed no evidence of recurrence of the tumor.

Conclusion: Giant cell tumor management has better outcomes with extended curettage with phenol crystal wash followed by bone grafting, cementing and plating. This study has shown no evidence of recurrence with the following technique at 18 months follow-up period. Phenol crystals can be used as a better alternative to liquid nitrogen for extended curettage.

Keywords: Giant cell tumor, aggressive, distal femur, curettage, phenol crystals, PMMA, allograft, plating

\section{Introduction}

Giant cell tumor (GCT) was first described by Cooper in 1818. Nelaton, later showed its local aggressiveness and Virchow revealed their malignant potential.

GCT is a benign but locally aggressive bone tumor commonly affecting the epiphyseometaphyseal region of long bones accounting for $5 \%$ of all primary bone tumors and $20 \%$ of all biopsy analyzed benign bone tumors ${ }^{[1]}$. The peak incidence being the third to fourth decades of life ${ }^{[2]}$.

Most common sites include the distal femur, proximal tibia and the distal radius in skeletally mature individuals. The sacrum, distal tibia, proximal humerus and proximal femur being the lesser involved ${ }^{[3]}$.

Even though benign, GCT may cause a substantial disturbance of the local bony architecture that can be particularly debilitating in peri-articular locations.

In the weight bearing long bones, the large sized GCTs are prone for pathological fractures even with an insignificant trauma.

GCT has a relatively high recurrence rate. Even though benign, metastases can occur in $1 \%$ to $9 \%$ of patients with GCT ${ }^{[4]}$. Studies have shown that the aggressive growth pattern of the tumor and local recurrence directly correlate with the risk of metastases ${ }^{[5]}$.

Curettage has been the preferred treatment for most cases of GCT. Chemical or physical agents work by inducing an additional circumferential area of necrosis to "extend" the curettage. 
Phenol, liquid nitrogen, bone cement, hydrogen peroxide, zinc chloride and more recently, argon beam cauterization have been employed as local adjuvants ${ }^{[6]}$.

\section{Case report}

An 18 year old male patient presented with 2 years history of pain and swelling above his right knee. The patient gives a history of an insignificant trauma to the same region two years back. The swelling was insidious in onset and gradually progressive. Pain was initially mild, diffuse and relieved on rest. But, the pain aggravated since the last 3 months, which made the patient consult the orthopaedician. On physical examination patient had a large bony swelling over the right distal femur with mild local rise of temperature. After radiograph, we arrived at a provisional diagnosis of giant cell tumor (figures 1 and 2). Patient underwent CT for detailed description of the tumor and also MRI to look for soft tissue involvement and periosteal reaction (figures 3 and 4). MRI showed $9.8 \times 5.7 \times 5.8 \mathrm{~cm}$ well defined multi-septated expansile eccentric lesion in epiphyseo-metaphyseal region of medial condyle of right femur, with thickened periosteal reaction and well defined sclerotic rim extenting to subarticular region suggestive of giant cell tumor. The patient underwent a short duration cycle of Denosumab for 2-3 months pre-operatively to facilitate less morbid surgery. Patient was then planned and taken up for surgery. Patient was operated under general anaesthesia. After achieving adequate exposure, a large cortical window was made for intra-lesional curettage using a high speed burr, phenol crystal wash was given, bone grafting and cementation with allograft mixed with bone cement Poly-methyl Methacrylate (PMMA) and medial condylar plating with titanium plate for right distal femur was done (figures 5 - 9). The curetted sample was sent for frozen section and histo-pathological examination. Intraoperative and post-operative periods were uneventful. Following surgery, the patient was immobilized with a long extension knee brace and non-weight bearing for 2 weeks continued. Histo-pathological examination report confirmed the diagnosis of giant cell tumor. The patient was allowed walker-assisted partial weight bearing after 2 weeks. The patient was followed up at $1,3,6,12$ and 18 months postoperatively. MRI was repeated at 12 months follow-up period which showed no evidence of recurrence of the tumor.
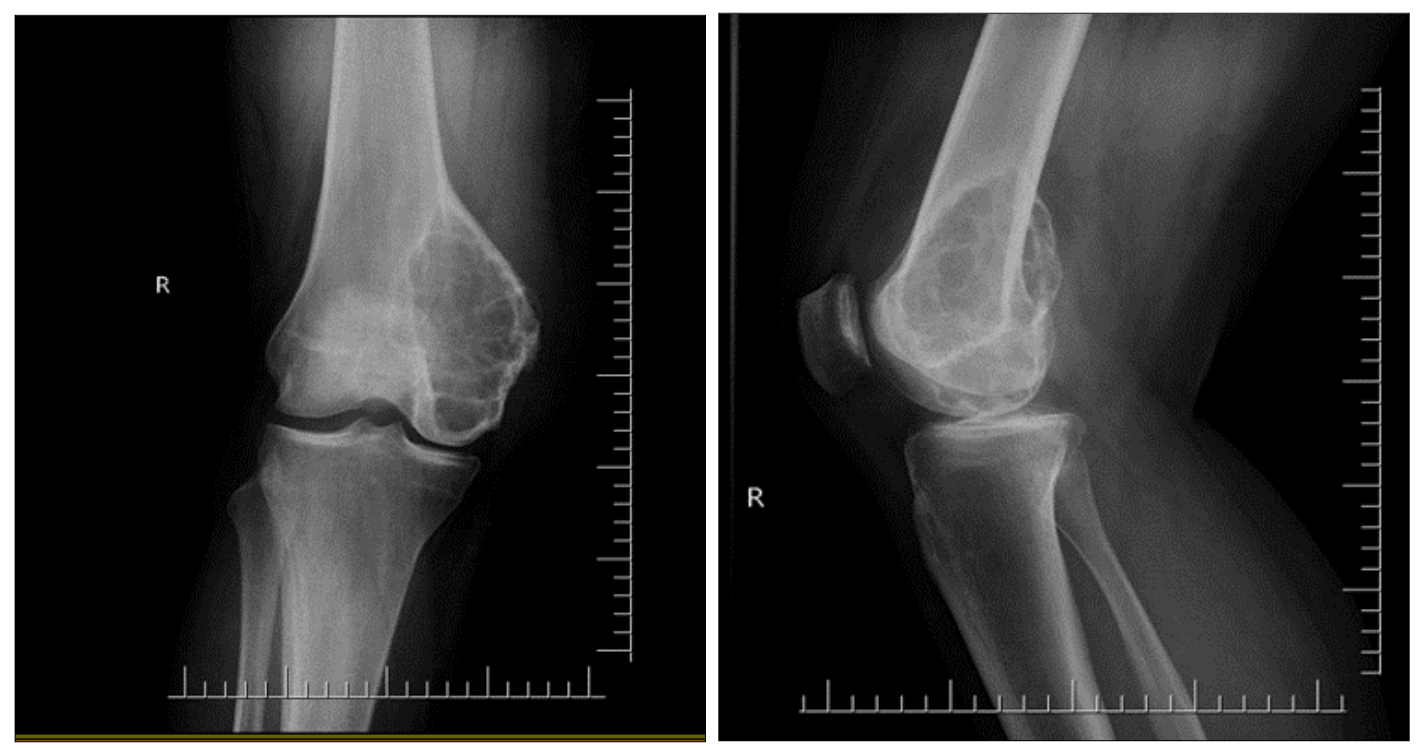

Fig 1 and 2: Showing AP and lateral radiographs of GCT of right distal femur
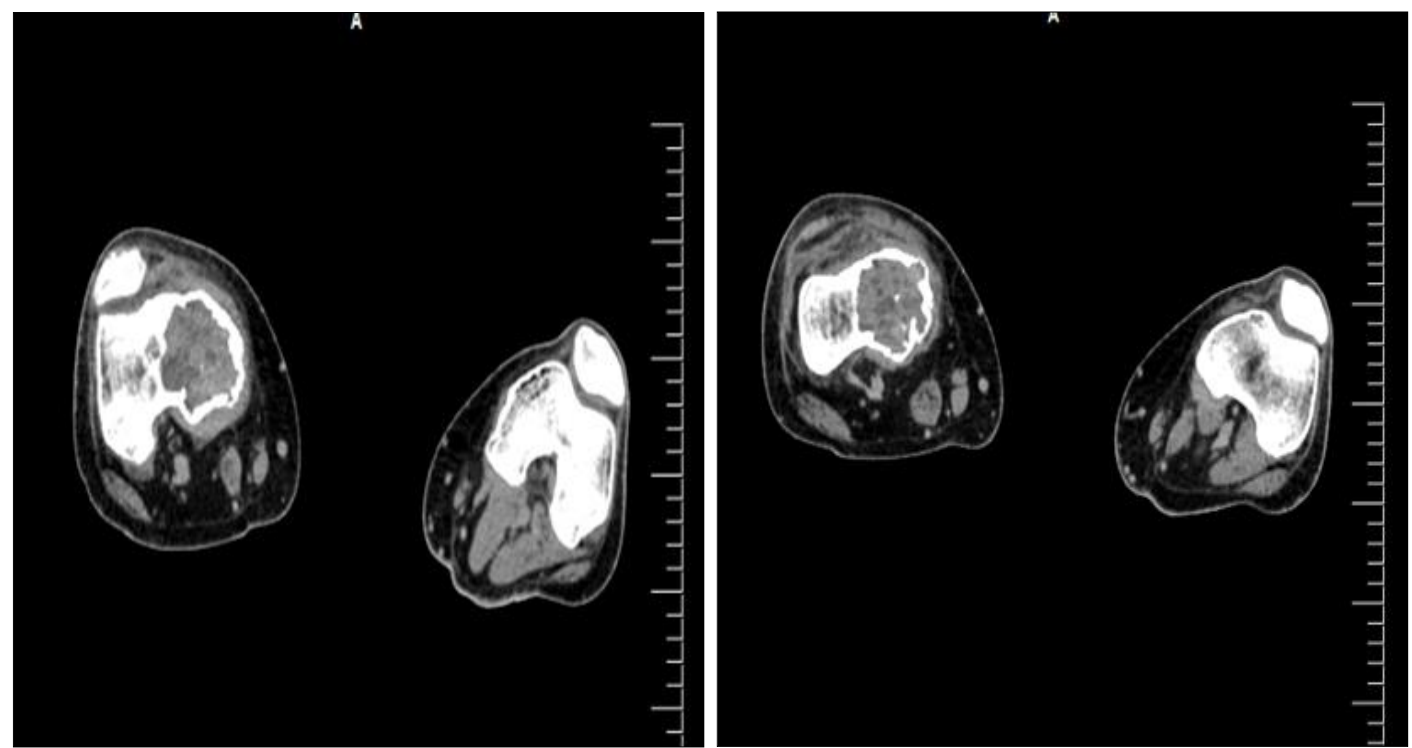

Fig 3: CT images showing the GCT of right distal femur 


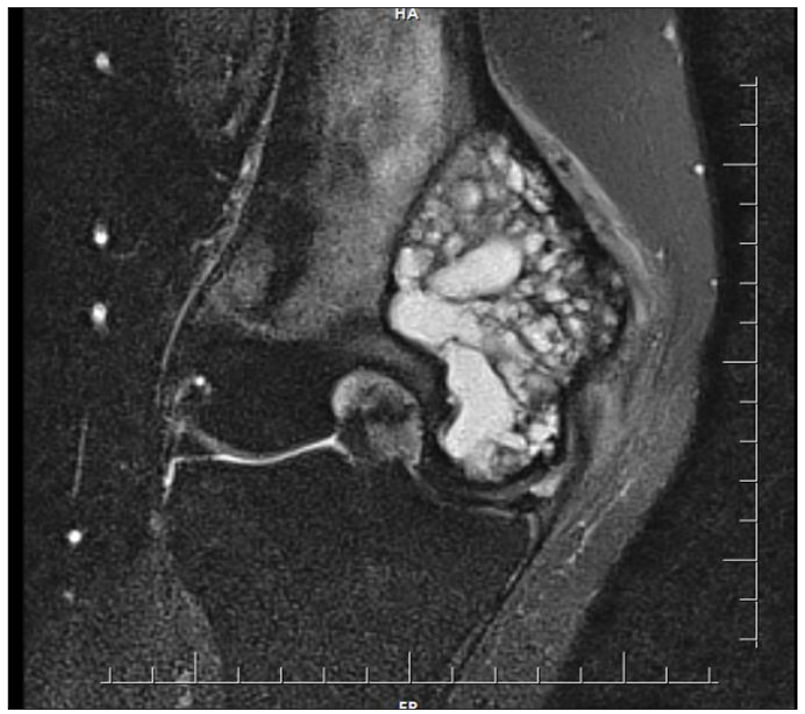

Fig 4: MRI image of GCT of right distal femur

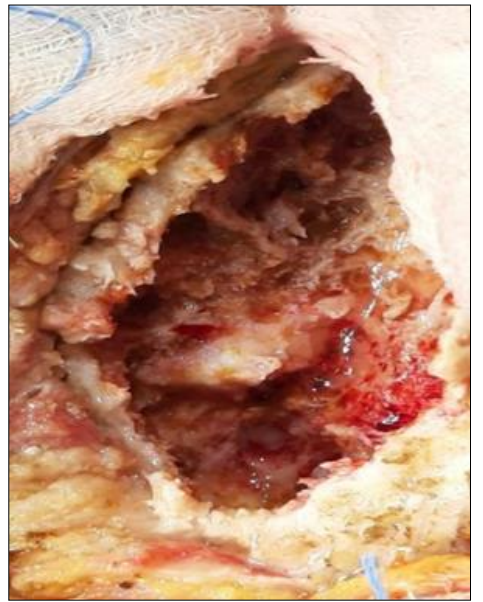

Fig 5:

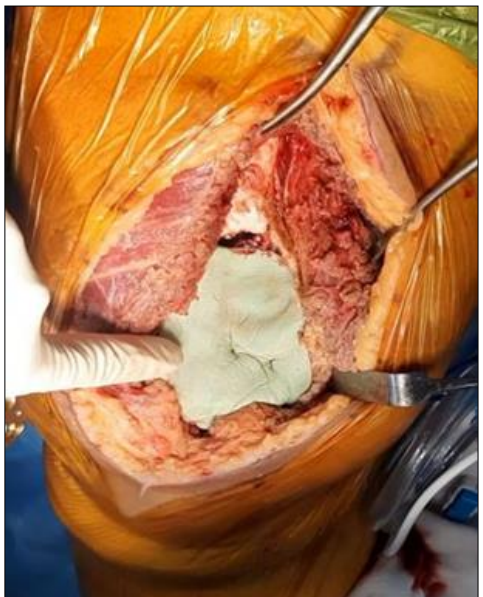

Fig 6:

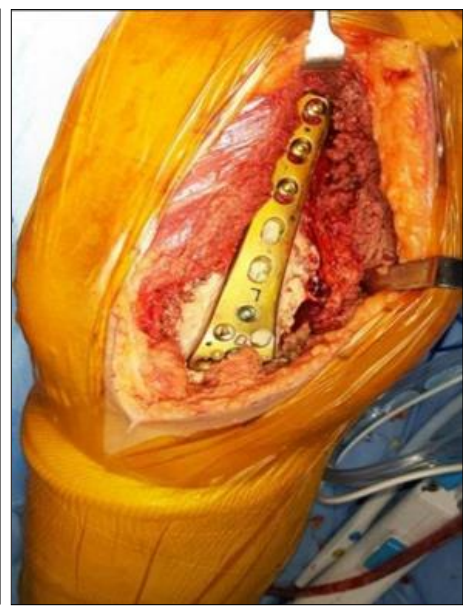

Fig 7:

Fig 5, 6 and 7: Intra-operative images of curettage, bone grafting with allograft mixed with bone cement and medial condylar plating
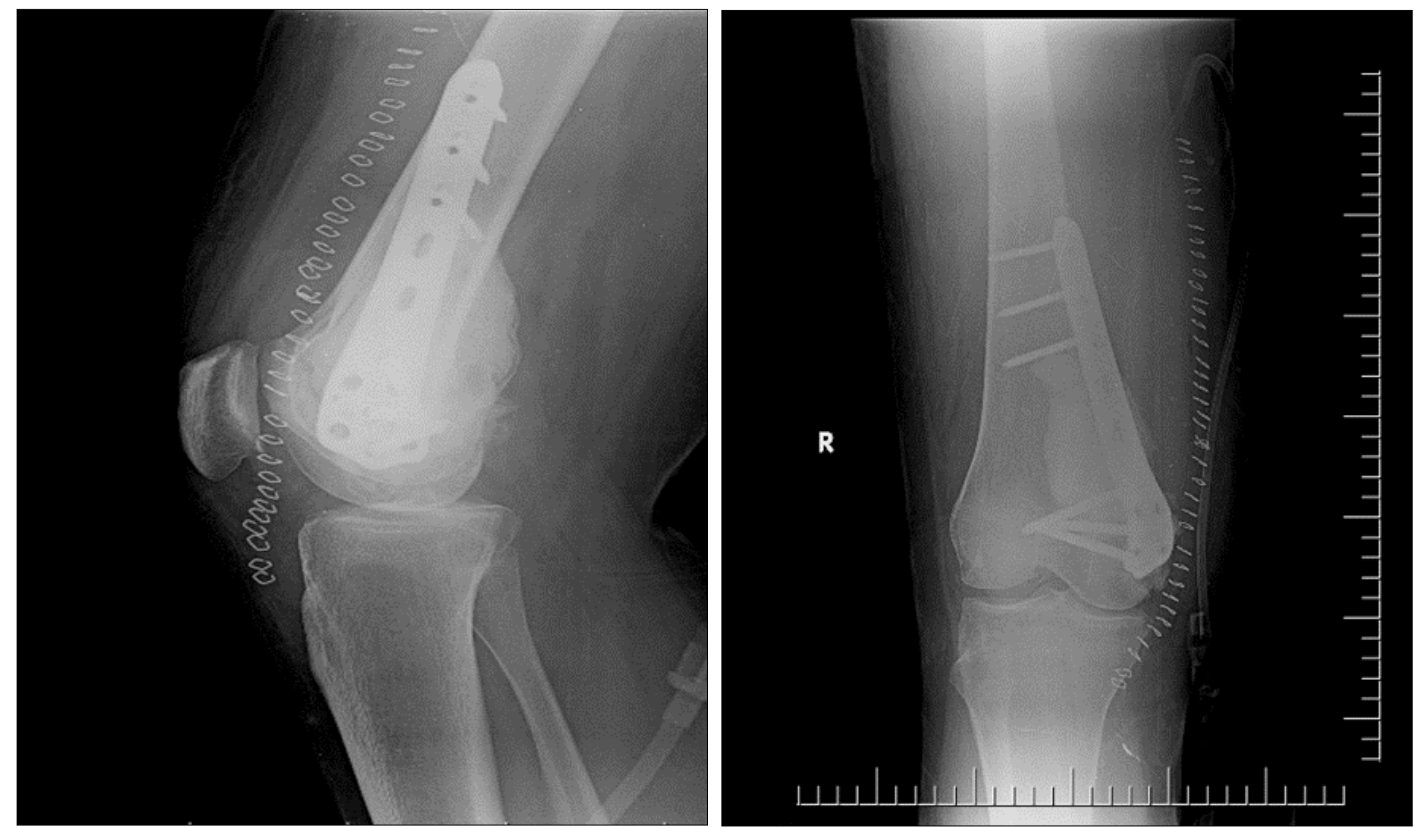

Fig 8 and 9: Post-operative AP and lateral radiographs of right distal femur

\section{Discussion}

Giant cell tumor located in the long bone periarticular locations has always been a challenging task for the operating surgeons. The risk of iatrogenic fracture during aggressive curettage and recurrence if adequate curettage not achieved, has to be taken into account at all times. 
The conventional methods of curettage alone with cementing and plating is now being augmented with the use of local adjuvants like phenol, liquid nitrogen, hydrogen peroxide, zinc chloride and argon beam cauterization ${ }^{[6]}$.

The studies have shown that non-oncological complications like secondary osteoarthritis, fracture, etc. were more common after use of liquid nitrogen and bone grafts $(33 \%)$ or liquid nitrogen and PMMA (27\%) compared with phenol and PMMA $(11 \%)^{[7]}$.

Phenolization is an effective and safe local adjuvant therapy for GCT ${ }^{[8]}$. Pre-operative short course of Denosumab was used with the aim to downstage the tumor and facilitate curettage [9].

In our patient, phenol crystal wash was used as a local adjuvant to "extend" the site of curettage, followed by bone grafting and cementation with allograft mixed with bone cement Poly-methyl Methacrylate (PMMA) and medial condylar plating.

A retrospective study done by Klenke et al. On 118 subjects, showed that the mean interval between surgery and recurrence was $16.3 \pm 12.4$ months (range, 4-50 months) [10].

A study by Saikia et al. On 32 subjects, showed that 11 $(34.4 \%)$ had local recurrence, of which 8 were of Campanacci's Grade III. The mean recurrence time was 14 months (range, 3-34 months). The two-year recurrence-free survivorship was $71.9 \%(n=23 / 32)^{[11]}$.

In our study, post-operatively the patient was followed up regularly up to 18 months.

\section{Conclusion}

Giant cell tumor management has better outcomes with extended curettage with phenol crystal wash followed by bone grafting, cementing and plating. This study has shown no evidence of recurrence with the following technique at 18 months follow-up period and gave a good functional outcome. Phenol crystals can be used as a better alternative to liquid nitrogen for extended curettage and also in reducing the nononcological complications such as secondary osteoarthritis, fracture, etc. associated with liquid nitrogen.

\section{Statement of consent}

Informed and Written consent has been taken from the patient to publish this as a case report for educational purpose.

\section{Conflict of interest: None}

\section{References}

1. Eckardt JJ, Grogan TJ. Giant cell tumor of bone. Clinical orthopedics and related research 1986;1(204):45-58.

2. McGrath PJ. Giant-cell tumour of bone: an analysis of fifty-two cases. The Journal of Bone and Joint Surgery. British 1972;54(2):216-29.

3. Bridge JA, Neff JR, Mouron BJ. Giant cell tumor of bone: chromosomal analysis of 48 specimens and review of the literature. Cancer genetics and cytogenetics 1992;58(1):2-13.

4. Bertoni F, Present D, Sudanese A, Baldini N, Bacchini P, Campanacci M. Giant-cell tumor of bone with pulmonary metastases. Six case reports and a review of the literature. Clinical orthopaedics and related research 1988;(237):275-85.

5. Siebenrock KA, Unni KK, Rock MG. Giant-cell tumour of bone metastasising to the lungs: a long-term follow- up. The Journal of bone and joint surgery. British 1998;80(1):43-7.

6. Turcotte RE. Giant cell tumor of bone. Orthopedic Clinics 2006;37(1):35-51.

7. Van Der Heijden L, Van Der Geest IC, Schreuder HB, Van De Sande MA, Dijkstra PS. Liquid nitrogen or phenolization for giant cell tumor of bone? a comparative cohort study of various standard treatments at two tertiary referral centers. JBJS 2014;96(5):e35.

8. Dürr HR, Maier M, Jansson V, Baur A, Refior HJ. Phenol as an adjuvant for local control in the treatment of giant cell tumour of the bone. European Journal of Surgical Oncology 1999;25(6):610-8.

9. Scoccianti G, Totti F, Scorianz M, Baldi G, Roselli G, Beltrami G, Franchi A, Capanna R, Campanacci DA. Preoperative denosumab with curettage and cryotherapy in giant cell tumor of bone: is there an increased risk of local recurrence? Clinical orthopaedics and related research 2018;476(9):1783.

10. Klenke FM, Wenger DE, Inwards CY, Rose PS, Sim FH. Giant cell tumor of bone: risk factors for recurrence. Clinical Orthopaedics and Related Research ${ }^{\circledR}$ 2011;469(2):591-9.

11. Saikia KC, Bhattacharyya TD, Bhuyan SK, Bordoloi B, Durgia B, Ahmed F. Local recurrences after curettage and cementing in long bone giant cell tumor. Indian journal of orthopaedics 2011;45:168-73. 